\title{
PREPARATION OF CALCIUM LACTOBIONATE AND LACTOBIONIC $\delta$-LACTONE
}

\author{
By Horace S. Isbell
}

ABSTRACT

Crystalline lactobionic $\delta$-lactone was obtained by dehydrating aqueous lactobionic acid by distillation with dioxane. This process is applicable for preparing lactones of other sugar acids. Lactobionic $\delta$-lactone is a new substance of particular importance for investigations in the carbohydrate field. It is more soluble than gluconic $\delta$-lactone, but it is not deliquescent and has a sweet taste. It melts at $195^{\circ}-196^{\circ} \mathrm{C}$.; in 5 percent water solution it gives $[\alpha]_{\mathrm{D}}^{20}=+54^{\circ}$ initially, decreasing in several hours to $+22^{\circ}$. These values agree with the rotations of the product obtained by the oxidation of lactose with bromine water in the presence of barium carbonate.

Calcium lactobionate was prepared in the crystalline state. It separates in hairlike crystals which form gelatinous mixtures with the mother liquor from which it is difficult to separate the pure substance. Consequently the crystalline salt is not suitable for the purification of lactobionic acid.

\section{CONTENTS}

I. Calcium lactobionate

1. Preparation of calcium lactobionate-calcium chloride.

2. Preparation of crystalline calcium lactobionate

II. Lactobionic $\delta$-lactone

1. Preparation of crystalline lactobionic $\delta$-lactone... 717

\section{CALCIUM LACTOBIONATE}

$$
\left(\mathrm{Ca}\left(\mathrm{C}_{12} \mathrm{H}_{21} \mathrm{O}_{12}\right)_{2}\right)
$$

The electrolytic method for the preparation of calcium lactobionate reported by Isbell and Frush, ${ }^{1}$ is so satisfactory that this salt may be readily prepared in any desired amount. Attempts to obtain a crystalline product, however, have been unsuccessful, and consequently it has been necessary to separate the lactobionic acid as a basic calcium salt. The use of the basic salt is objectionable because the lime causes degradation of any unoxidized sugar and thus prevents the satisfactory operation of a continuous process such as that described by Isbell, Frush, and Bates ${ }^{2}$ for calcium gluconate.

If a crystalline form of calcium lactobionate could be separated directly from the solution obtained by the oxidation of lactose its

\footnotetext{
1 Isbell and Frush, B. S. Jour. Research, vol. 6 (RP328), p. 1151, 1931.

Isbell, Frush and Bates, B. S. Jour. Research, vol. 8 (RP436), p. 571, 1932.
} 
preparation would be simplified. This will be seen from the following equation:

$$
\begin{gathered}
\stackrel{\text { Lactose }}{\mathrm{C}_{12} \mathrm{H}_{22} \mathrm{O}_{11}}+\mathrm{CaCO}_{3}+\mathrm{H}_{2} \mathrm{O}+\underset{\mathrm{Catalyst}}{\mathrm{CaBr}_{2}} \stackrel{\text { Electrolysis }}{\longrightarrow} \underset{\mathrm{Ca}}{\longrightarrow} \mathrm{Ca}\left(\mathrm{C}_{12} \mathrm{H}_{21} \mathrm{O}_{12}\right)_{2}+ \\
\mathrm{CO}_{2}+2 \mathrm{H}_{2}+\mathrm{CaBr}_{2}
\end{gathered}
$$

Lactobionic acid was made first by Fischer and Meyer ${ }^{3}$ by the oxidation of lactose with bromine. They prepared the amorphous calcium salt but were unable to bring it to crystallization. Subsequently Ruff and Ollendorff ${ }^{4}$ reported a substance, which they believed to be crystalline, prepared by precipitating crude calcium lactobionate with alcohol. They did not describe the product in sufficient detail to reveal whether the substance was actually crystalline. By essentially the same procedure C. S. Hudson ${ }^{5}$ and the writer obtained a granular precipitate in which no double refraction could be observed.

After many attempts the writer has now prepared crystalline calcium lactobionate. The first crystals were obtained from an aqueous solution of calcium lactobionate made from basic calcium lactobionate, which had been prepared from calcium lactobionate-calcium chloride. $^{6}$ Calcium lactobionate resembles calcium rhamnonate in that it separates in hairlike crystals which form in brushlike groups frequently oriented so that all the crystals in a given group affect polarized light in the same manner. Various procedures have been tried in vain to determine conditions for separating large and compact crystals. The crystalline salt apparently contains water of crystallization, but on account of the difficulty of separating it from the mother liquor it is not possible to distinguish between the occluded water and chemically bound water. The product when dried 8 hours at $60^{\circ} \mathrm{C}$. in vacuo contains 4.74 percent calcium, which corresponds to a formula, $\mathrm{Ca}\left(\mathrm{C}_{12} \mathrm{H}_{21} \mathrm{O}_{12}\right)_{2} .5 \mathrm{H}_{2} \mathrm{O}$.

Unfortunately the salt is not easily separated in the electrolytic process, but its tendency to form gelatinous masses may prove of value in other fields.

\section{PREPARATION OF CALCIUM LACTOBIONATE-CALCIUM CHLORIDE}

Equimolecular proportions of calcium chloride and calcium lactobionate, prepared from lactose as described in Research Paper No. 328 , were dissolved in water. The solution was evaporated in vacuo to a thin sirup from which crystalline calcium lactobionate-calcium chloride separated. The crude salt was recrystallized from water and dried in air at room temperature.

Analysis calculated for $\mathrm{Ca}\left(\mathrm{C}_{12} \mathrm{H}_{21} \mathrm{O}_{12}\right)_{2} \cdot \mathrm{CaCl}_{2} \cdot 6 \mathrm{H}_{2} \mathrm{O}: \mathrm{Ca}, 8.23 ; \mathrm{Cl}$, $\alpha 7.29$. Found: $\mathrm{Ca}, 8.25 ; \mathrm{Cl}, 7.29$. It gave $[\delta]_{\mathrm{D}}^{20}=+20.0$. $\quad(1.3249 \mathrm{~g}$ dissolved in $25 \mathrm{ml}$ of $\mathrm{H}_{2} \mathrm{O}$ read $6.13^{\circ} \mathrm{S}$. in a $2 \mathrm{dm}$ tube.)

The mutarotation of lactobionic acid was determined from this salt in the following manner: A $6.0843 \mathrm{~g}$ sample of calcium lactobionate-calcium chloride was placed in a flask and $50.125 \mathrm{~g} 0.25 \mathrm{~N}$

\footnotetext{
3 Fischer and Meyer, Ber., vol. 22, p. 361, 1889.

4 Ruff and Ollendorff, Ber., vol. 23, p. 1805, 1900.

5 Hudson and Isbell, B. S. Jour. Research, vol. 3 (RP82), p. 57, 1929.

6 Stoll and Kussmaul, U.S. Patent No. 1648368, dated Nov. 8, 1927.
} 
$\mathrm{HCl}$ was added with a pipette. After $3,5,10,15,30,60$, and 120 minutes at $20^{\circ} \mathrm{C}$. the solution read in a $2 \mathrm{dm}$ tube $+7.60^{\circ},+7.85^{\circ}$, $+8.23^{\circ},+8.55^{\circ},+9.13^{\circ},+9.43^{\circ}$, and $+9.55^{\circ} \mathrm{S}$.

The specific rotations which are illustrated in figure 1 by the curve marked lactobionic acid are based on the weight of lactone $\left(\mathrm{C}_{12} \mathrm{H}_{20} \mathrm{O}_{11}\right)$ equivalent to the salt used. The conversion factor, 0.3462 , was used for changing the degrees sugar to angular rotation. The density of the solution was $1.0493 \mathrm{~g} / \mathrm{ml}$.

\section{PREPARATION OF CRYSTALLINE CALCIUM LACTOBIONATE}

A $235 \mathrm{~g}$ sample of crystalline calcium lactobionate-calcium chloride was added in small portions, with stirring, to a suspension of 100 $\mathrm{g}$ of calcium oxide in 1 liter of hot water. After standing several

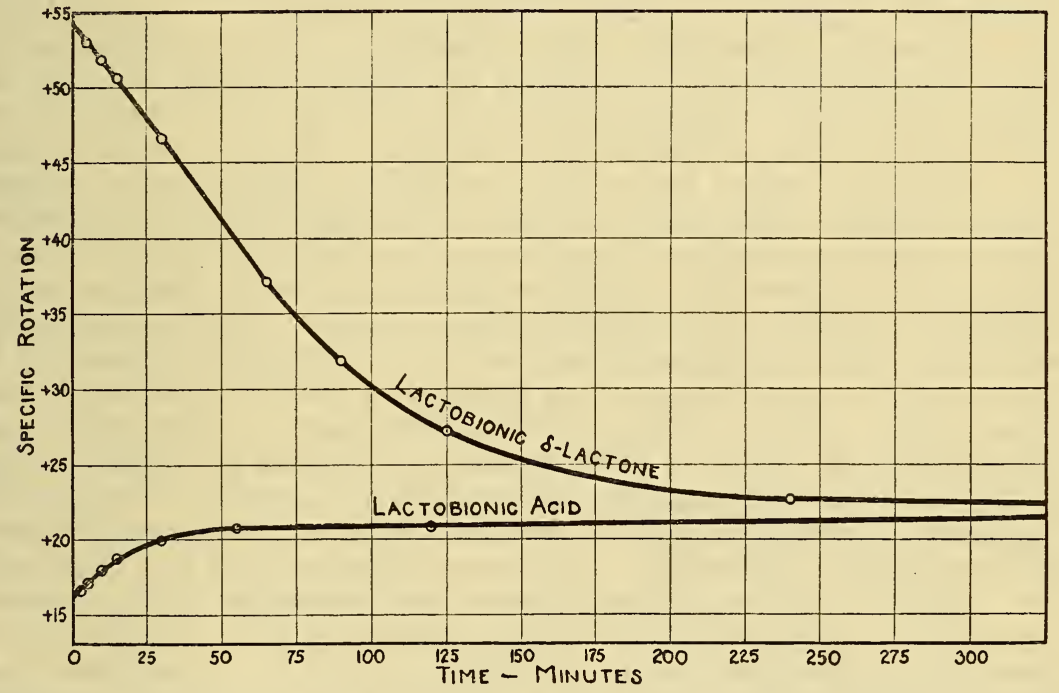

FIGURE 1.-Change in specific rotation at $20^{\circ}$ C. of $0.25 \mathrm{~N}$ aqueous lactobionic acid and $0.25 \mathrm{~N}$ lactobionic $\delta$-lactone.

hours the resulting basic calcium lactobionate was separated by filtration and washed with lime water until free from chloride. The basic salt (333 g air dried) was suspended in 2 liters of water and carbonated. The resulting solution of calcium lactobionate was filtered and evaporated to a thick sirup (refractive index $=1.4583$ at $20^{\circ} \mathrm{C}$.). After standing several weeks the product solidified. A microscopic examination showed double refractive slender needlelike crystals. The product was dried, without filtration, and pulverized. The crude product weighed $215 \mathrm{~g}$ and contained 4.43 percent calcium.

The crude calcium lactobionate was purified by dissolving $40 \mathrm{~g}$ in $60 \mathrm{ml}$ of water, filtering, and adding methyl alcohol until the solution was nearly saturated. Care was taken not to add sufficient alcohol to cause a permanent precipitate of amorphous material. The resulting solution was seeded with crystalline calcium lactobionate and stirred for several hours. The final product contained long slender needle crystals which were separated by filter-pressing. The resulting 
filter cake was dried 24 hours at $60^{\circ} \mathrm{C}$ in vacuo. The product in water solution gave $[\alpha]_{\mathrm{D}}^{20}=+23.7^{\circ}$. A $1.5745 \mathrm{~g}$ sample in $25 \mathrm{ml}$ read $8.63^{\circ} \mathrm{S}$. in a $2 \mathrm{dm}$ tube. Analysis: Calculated for $\mathrm{Ca}\left(\mathrm{C}_{12} \mathrm{H}_{21} \mathrm{O}_{12}\right)_{2}$. $5 \mathrm{H}_{2} \mathrm{O}: \mathrm{Ca}, 4.74$. Found: $\mathrm{Ca}, 4.74$.

\section{LACTOBIONIC $\delta$-LACTONE}

$$
\left(\mathrm{C}_{12} \mathrm{H}_{20} \mathrm{O}_{11}\right)
$$

In a previous publication the writer and C. S. Hudson ${ }^{7}$ showed that the lactone of lactobionic acid is formed by the oxidation of lactose prior to the formation of the free acid. The confirmation of this important observation required the preparation of the $\delta$-lactone. Although a number of investigators have prepared aqueous lactobionic acid, heretofore the crystalline lactone has not been reported. Application of one of the newer solvents, dioxane, ${ }^{8}$ to the problem has lead to the preparation of the substance in its crystalline form. It was obtained first by evaporating an aqueous dioxane solution of lactobionic acid to dryness, adding more dioxane, and mixing in a rotating flask until crystallization occurred. The new substance is very soluble in water, but nearly insoluble in ethyl alcohol, ether, acetone, dioxane, and similar solvents. It is slightly soluble in glacial acetic acid and crystallizes therefrom in transparent prismatic prisms. It also dissolves readily in ethylene glycol. It tastes about as sweet as lactose, which is very unusual for a lactone. It is decomposed slowly by water, giving lactobionic acid, but when freshly dissolved it reacts neutral. As illustrated in figure 1 , a $0.25 \mathrm{~N}$ solution of the lactone gives $[\alpha]_{\mathrm{D}}^{20}=+54^{\circ}$ initially, decreasing in the course of several hours to $+22.6^{\circ}$. The change in rotation is caused by the hydrolysis of the lactone with the formation of free lactobionic acid. Inasmuch as lactobionic acid cannot form a $\gamma$-lactone the equilibrium solution consists primarily of a mixture of the free acid and $\delta$-lactone. The specific rotation of lactobionic acid prepared from calcium lactobionate-calcium chloride (curve 2 ) was found to be $+16^{\circ}$ initially, increasing in the course of several hours to $+21^{\circ}$. A calculation of the composition of the equilibrium solution from the specific rotation of the lactone $(+54)$ and the acid $(+16)$ shows that an aqueous solution in equilibrium $(+22)$ contains approximately 16 percent lactone and 84 percent acid. This is a relatively large proportion of free acid, and hence one might be able to crystallize the acid from aqueous solution provided crystals were available for nucleation.

The specific rotation of the product ${ }^{9}$ obtained by the oxidation of $\beta$-lactose was $+52.4^{\circ} 10$ minutes after the beginning of the reaction. This agrees with the rotation of lactobionic $\delta$-lactone, $+51.9^{\circ} 10$ minutes after solution. The subsequent changes in rotation are comparable, thus supporting the conclusion that lactobionic $\delta$-lactone is formed by the oxidation of lactose by bromine water in slightly acid solution rather than lactobionic acid as previously believed.

\footnotetext{
7 Hudson and Isbell, B.S.Jour. Research, vol. 8 (RP418), p. 327,1932 .
8 The writer has found that dioxane can be used to advantage in the preparation of many lactones. Some examples are reported by Isbell and Frush, B.S.Jour. Research, vol. 11 (RP613), p. 649, 1933.

$\because$ The mutarotation of this product was given in Research Paper No. 441, p. 621, figure 3.
} 


\section{PREPARATION OF CRYSTALLINE LACTOBIONIC $\delta\llcorner L A C T O N E$}

$$
\left(\mathrm{C}_{12} \mathrm{H}_{20} \mathrm{O}_{11}\right)
$$

A solution of lactobionic acid was prepared by the addition of $7.6 \mathrm{~g}$ of oxalic acid to $50 \mathrm{~g}$ of $\mathrm{Ca}\left(\mathrm{C}_{12} \mathrm{H}_{21} \mathrm{O}_{12}\right)_{2} .5 \mathrm{H}_{2} \mathrm{O}$ dissolved in $100 \mathrm{ml}$ of hot water. After filtration the solution was cooled to room temperature and evaporated in vacuo to a sirup. The aqueous sirup was dehydrated by the addition of $50 \mathrm{ml}$ of dioxane, followed by distillation in vacuo until dry. The residue was mixed with $25 \mathrm{ml}$ of dioxane and $25 \mathrm{ml}$ of toluene and the process repeated. A friable material remained, which was titurated with $100 \mathrm{ml}$ of dioxane and then allowed to stand with stirring until a portion of the product had crystallized. This required several weeks. The dioxane was removed by filtration and the residue dried at $60^{\circ} \mathrm{C}$. in vacuo. The crude product $(40 \mathrm{~g})$ was digested with $500 \mathrm{ml}$ of boiling acetic acid. After cooling, the crystals were collected on a filter washed with acetic acid and finally dried in vacuo. About $35 \mathrm{~g}$ of material was obtained from $50 \mathrm{~g}$ of calcium lactobionate. The crude product melted with decomposition at $185^{\circ}$ to $190^{\circ} \mathrm{C}$. and gave $[\alpha]_{\mathrm{D}}^{20}=+49^{\circ}$, initially. It was recrystallized by dissolving it in a small amount of water and adding glacial acetic acid until slightly turbid, followed by distillation in vacuo until about half of the solvent was removed. After cooling and seeding the resulting sirup with some crystals previously secured, nearly pure lactobionic $\delta$-lactone was obtained. The specific rotation $(+54)$ of the product was the same as that of crystals obtained from hot glacial acetic acid, but the melting point was slightly lower $\left(185^{\circ}\right.$ to $195^{\circ}$ C.). About $3 \mathrm{~g}$ of lactone was dissolved in $500 \mathrm{ml}$ of boiling glacial acetic acid; about $1 \mathrm{~g}$ of crystalline lactobionic $\delta$-lactone separated on cooling. The product melted with decomposition at $195^{\circ}$ to $196^{\circ} \mathrm{C}$. and gave $[\alpha]_{\mathrm{D}}^{20}=+54^{\circ}$, initially, decreasing in several hours to $+22^{\circ}$. The mother liquors can be used as a solvent for subsequent crystallizations.

The lactone is readily hydrolyzed to give lactobionic acid and may be titrated with standard alkali and phenolphthalein. A $0.5861 \mathrm{~g}$ sample of the lactone required $17.31 \mathrm{ml}$ of $0.1 \mathrm{~N} \mathrm{Ba}(\mathrm{OH})_{2}$ for saponification; the amount calculated for $\mathrm{C}_{12} \mathrm{H}_{20} \mathrm{O}_{11}$ is $17.23 \mathrm{ml}$.

A $2.2355 \mathrm{~g}$ sample of the lactone $\left(\mathrm{C}_{12} \mathrm{H}_{20} \mathrm{O}_{11}\right)$ in $25 \mathrm{ml}$ of water solution at $20^{\circ} \mathrm{C}$. read on a Bates saccharimeter in a $2 \mathrm{dm}$ tube $+27.38^{\circ},+26.80^{\circ},+26.20^{\circ}+24.10^{\circ},+19.18^{\circ},+16.50^{\circ},+14.07^{\circ}$, and $+11.67^{\circ}$ after $5,10,15,30,65,90,125$, and 240 minutes. $[\alpha]_{\mathrm{D}}^{20}$ $=+53.0^{\circ},+51.9^{\circ},+50.7^{\circ},+46.7^{\circ},+37.1^{\circ},+31.9^{\circ},+27.2^{\circ}$, and $+22.6^{\circ}$, respectively..$^{10}$

A $1.2498 \mathrm{~g}$ sample of the lactone in $25 \mathrm{ml}$ of water solution at $20^{\circ} \mathrm{C}$. read in a $2 \mathrm{dm}$ tube:

$$
\begin{aligned}
& +15.43^{\circ},+15.21^{\circ},+14.87^{\circ} \text {, and }+6.45^{\circ} \mathrm{S} \text { after } \\
& 2,5,10, \text { and } 1,440 \text { minutes. } \\
& {[\alpha]_{\mathrm{D}}^{20}=+53.4^{\circ},+52.7^{\circ},+51.5^{\circ}, \text { and }+22.3^{\circ} \text {, respectively }} \\
& \text { Washington, August } 26,1933 .
\end{aligned}
$$

${ }^{10}$ The conversion factor 0.3462 was used. International Critical Tables, vol. II, p. 336 . 